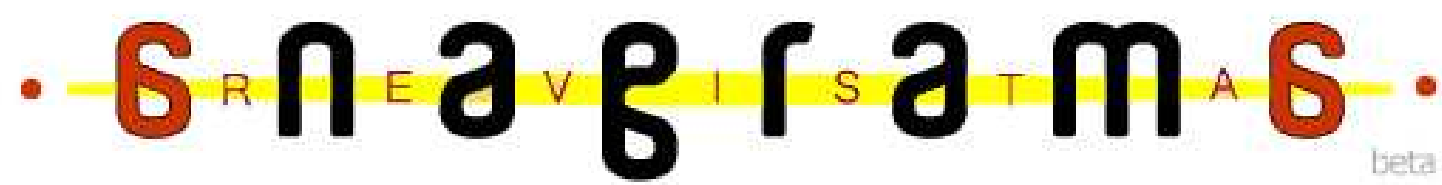

\section{A mídia como Meio de Reprodução do Poder e da Disciplina no contexto da Tríplice Fronteira}

\section{João Victor Borba Moura e Silua' \\ Ada Cristina Machado da Silueira?}

\section{Resumo}

A proposta deste artigo é analisar as formas de enquadramento jornalístico empregado por um jornal local na Tríplice Fronteira entre Brasil, Argentina e Paraguai. Tal análise procura investigar o papel de um diário local na reprodução do poder e da disciplina presentes em outras áreas da sociedade, perfazendo a análise dos discursos e o uso do vocabulário em notícias com os termos "Argentina", "favela", "fronteira", "Paraguai" e "periferia" no ano de 2006. Para isso, baseia-se nas ideias do filósofo francês Michel Foucault e em seus conceitos de Poder e Disciplina.

Palauras-chaue: Fronteira; Disciplina; Poder; Michel Foucault.

\section{Introdução}

A tríplice fronteira é noticiada como uma das áreas mais conturbadas da América do Sul. Quase sempre em efervescência política, é palco de greves, discordâncias diplomáticas e desavenças jurídicas. É um local onde aquilo que é decidido nas altas cúpulas governamentais toma forma, existe materialmente - como o combate ao contrabando e ao tráfico de drogas, o estabelecimento de taxas alfandegárias e a negociação de taxas energéticas. O estudo deste conturbado sistema torna-se necessário para entendermos melhor os desafios da globalização e da sociedade em que vivemos,

${ }^{1}$ Estudante de Graduação $7^{\circ}$. semestre do Curso de Jornalismo da UFSM. Bolsista PROBIC/FAPERGS, email: jvmouraesilva@gmail.com

${ }^{2}$ Orientadora do trabalho. Professora do Departamento de Ciências da Comunicação da UFSM, e-mail: ada.machado@pq.cnpq.br 
especialmente no que diz respeito aos sistemas de poder e disciplina aos quais entramos em contato todos os dias.

Este artigo procura identificar, dentro do conteúdo noticioso do jornal "A Gazeta do Iguaçu", as formas de reprodução do poder e da disciplina na mídia. Para tal, leva em conta termos e abordagens usadas pelo jornal na caracterização da região da Tríplice Fronteira, constituída basicamente por três cidades: Ciudad del Este (Paraguai), Foz do Iguaçu (Brasil) e Puerto Iguazú (Argentina).

Partindo da hipótese de que o jornal pode ter papel-chave na reprodução da disciplina e do poder encontrados em outros organismos da sociedade, avalia a atividade discursiva no tratamento de assuntos da cidade sede do jornal, Foz do Iguaçu, e das cidades que fazem fronteira com esta.

Tal avaliação será feita levando-se em conta as matérias publicadas no decorrer do ano de 2006 no "Caderno 1" do periódico, de conteúdo jornalístico. Num primeiro momento, pesquisou-se em todas as matérias por cinco palavras-chave: "Argentina", "favela", "fronteira", "Paraguai" e "periferia", além de termos adjacentes como paraguaio(a), argentino(a), favelado(a) e periférico(a). Posteriormente, com tal busca realizada, foram retiradas para análise 22 matérias de um total de 1413 encontradas, levando em conta as precauções metodológicas de Foucault (2008) para o estudo do poder.

Para que esta análise fosse feita, usou-se como base as ideias de Michael Foucault sobre poder e disciplina, em especial as obras Microfísica do Poder (2008) e Vigiar e Punir (1997). A escolha por Foucault como alicerce é justificada na extensão de sua obra quanto aos conceitos de disciplina e poder.

Este artigo integra o projeto "Brasil, mostra tua cara: a ambivalência de fronteiras e favelas na cobertura jornalística sobre as periferias", coordenado pela Prof ${ }^{\mathrm{a}}$. Dra ${ }^{\mathrm{a}}$. Ada Cristina Machado da Silveira, da Universidade Federal de Santa Maria, Rio Grande do Sul.

\section{A Disciplina}

Michel Foucault, ao fazer um apanhado histórico de como chegamos a sociedade contemporânea, com suas leis e formas de disciplinar próprias escreve quanto à disciplina:

A “disciplina” não pode se identificar com uma instituição nem com um aparelho; ela é um tipo de poder, uma modalidade para exercê-lo, que comporta todo um conjunto de instrumentos, de técnicas, de procedimentos, de níveis de aplicação, de alvos; ela é uma "física" ou uma "anatomia" do poder, uma tecnologia. (FOUCAULT, 1997: 177) 
Foucault caracteriza a disciplina como uma tecnologia, transporta tal experiência para a sociedade, usando como elemento básico os conceitos da prisão panóptica de Bentham:

\begin{abstract}
Na periferia uma construção em anel; no centro, uma torre; esta é vazada de largas janelas que se abrem sobre a face interna do anel; a construção periférica é dividida em celas, cada uma atravessando toda a espessura da construção; elas têm duas janelas, uma para o interior, correspondente às janelas da torre; outra, que dá para o exterior, permite que a luz atravesse a cela de lado a lado. Basta então colocar um vigia na torre central, e em cada cela trancar um louco, um doente, um condenado, um operário ou um escolar. Pelo efeito da contraluz, pode-se perceber da torre, recortando-se exatamente sobre a claridade, as pequenas silhuetas cativas nas celas da periferia [...] Daí o efeito mais importante do Panóptico: induzir no detento o estado consciente e permanente de visibilidade que assegura o funcionamento automático do poder. (FOUCAULT, 1997: 165-6)
\end{abstract}

Ou seja, tal instrumento permitiria uma vigilância constante de todos os presos. Como também afirmaria a presença desse poder sem que ele tenha um corpo, silhueta. $\mathrm{O}$ poder torna-se invisível para o condenado, que não pode mais visualizá-lo. A dúvida suscitada pelo desconhecimento disciplinaria o condenado.

Para Foucault, na sociedade várias instituições sobem à torre panóptica para exercerem a disciplina:

Pode ficar a cargo seja de instituições "especializadas" (as penitenciárias ou as casas de correção do século XIX), seja de instituições que dela se servem como instrumento essencial para um fim determinado (as casas de educação, os hospitais), seja de instâncias preexistentes que nela encontram maneira de reforçar ou de reorganizar seus mecanismos internos de poder (um dia se precisará mostrar como as relações intrafamiliares, essencialmente na célula pais-filhos, se "disciplinaram", absorvendo desde a era clássica esquemas externos, escolares, militares, depois médicos, psiquiátricos, psicológicos, que fizeram da família o local de surgimento privilegiado para a questão disciplinar do normal e do anormal), seja de aparelhos que fizeram da disciplina seu princípio de funcionamento interior (disciplinação do aparelho administrativo a partir da época napoleônica), seja enfim de aparelhos estatais que tem por função não exclusiva, mas principalmente fazer reinar a disciplina na escala da sociedade (a polícia). (FOUCAULT, 1997: 177-8)

O processo de panoptização da sociedade ganha força com o passar dos séculos XVIII e XIX, e aos poucos sai de partes localizadas da sociedade, como escolas, quartéis e penitenciárias para perpassá-la, atingi-la globalmente. Se antes a disciplina era para os desajustados e necessitados, aos poucos torna-se ferramenta de controle total, tornando-se importante "figura de tecnologia política" (FOUCAULT, 1997).

A partir dessa referência, entendemos que a disciplina não ocorre somente pela punição direta, mas sim nas demonstrações de poder indiretas, que possibilitam a ideia de 
vigilância a todo o momento, exercido por diversas instituições. $\mathrm{Na}$ sociedade contemporânea podemos considerar que outro elemento se une a essas instituições, os meios de comunicação.

\section{OPoder}

Para produção do presente estudo, foram levadas em conta as "precauções metodológicas" (FOUCAULT, 2008). Constituídas por cinco critérios para o estudo do poder: tratar o poder nos contextos mais locais, onde penetra instituições, corporifica-se em técnicas e intervenções materiais; estudar o poder onde sua intenção, se é que ela existe, está completamente investida em práticas reais e efetivas; analisar o poder como algo que circula, que só funciona em cadeia e que perpassa a todos, não sendo propriedade de alguém, ou alguma coisa, mas sendo exercido e sofrido por todos; analisar a maneira como os fenômenos, as técnicas e os procedimentos de poder atuam nos níveis mais baixos e como se deslocam, se expandem e se modificam para um contexto mais global, de forma ascendente; e por fim não ver o poder como algo baseado em ideologias, e sim como elemento que para exercer o poder forma e organiza aparelhos de saber para as ideologias (FOUCUALT,2008).

Dessa forma, a escolha de um meio de comunicação local era imperativa, selecionando-se o jornal diário Gazeta do Iguaçu, de maior distribuição do lado brasileiro da fronteira, como elemento de análise. Num primeiro momento, realizou-se uma pesquisa nas edições do ano de 2006 em busca de cinco palavras-chave: "Argentina", "favela", "fronteira", "Paraguai" e "periferia", além de termos adjacentes como paraguaio(a), argentino(a), favelado(a) e periférico(a). Tal busca foi feita no acervo on-line do periódico, que permite aos assinantes acesso completo ao material já veiculado no jornal desde outubro de 2005.

Para que essas palavras-chave fossem localizadas foi necessária pesquisa edição por edição, matéria por matéria, visto a impossibilidade de busca direta por palavras-chave no atual formato do acervo digital do jornal. As matérias pesquisadas foram aquelas que constituíam as dez editorias do chamado "Caderno 1" (Editorial, Cidade, Região, Nacional, Internacional, Geral, Polícia, Política, Esporte e Economia), de conteúdo jornalístico. Ao fim da busca 1413 matérias continham um ou mais dos termos pesquisados. Depois do levantamento destes dados, recortou-se um corpus de análise, levando em consideração as cinco precauções metodológicas para o estudo do poder 
(FOUCAULT, 2008). As matérias selecionadas são de quatro editorias: Cidade, com a maior parte dos textos, 11; Polícia, com 9; e mais duas matérias, das editorias de Internacional e Política.

\section{Obseruações Panópticas}

Baseando-se nas matérias encontradas, podemos dizer que não raro, nas notícias da editoria Polícia, a correlação Paraguai-Violência é feita. Na chamada "ronda policial" é usual a conexão entre as mortes ocorridas na cidade à proximidade com o país vizinho. Das matérias veiculadas no decorrer do ano de 2006 em que foram encontradas algumas das palavras-chave, 525 são da editoria policial, 37,1\% do total, 1413. Destas 525, $72 \%$ (378) delas fazem algum tipo de menção ao Paraguai.

Algumas matérias merecem destaque na editoria de Polícia. O que se pode perceber são notícias que frequentemente isentam a polícia de culpa nas ações criminosas da cidade, e o deslocamento da responsabilidade pelos crimes na localização geográfica da cidade de Foz do Iguaçu e, em decorrência disso, nos países e moradores da tríplice fronteira.

É o caso da notícia do dia 29 de junho de 2006: "Investigadores do $2^{\circ}$ DP prendem casal de ladrões". O subtítulo da matéria é "Paraguaios" e o texto discorre sobre seus furtos: "Nenhum dos produtos era alimentício, somente de valor alto e de fácil comércio". O caso serve como exemplo: a mesma leitura pode ser feita em diversas notas que envolvem brasileiros a diversos tipos de crime (considerando as 525 matérias pesquisadas da editoria Polícia), mas em nenhuma delas foi encontrada o subtítulo "brasileiros".

$\mathrm{O}$ esforço em isentar o órgão policial ${ }^{4}$ aparece em diversas notícias analisadas. $\mathrm{Na}$ matéria veiculada no dia 11 de julho "Seis pessoas são mortas em $24 \mathrm{~h}$ " retira-se a responsabilidade da polícia logo no subtítulo: “Apesar do esforço da polícia, nenhum dos assassinos foi localizado".

A linguagem de diversas notícias também é diferenciada para os órgãos policiais. Em diversas matérias analisadas os agentes de Polícia são descritos como "servidores". Tal benevolência não se estende aos suspeitos, normalmente descritos como "marginais" ou

\footnotetext{
${ }^{3}$ Jargão jornalístico que descreve o trabalho de checar informações de crimes (que tenham ocorrido ou que esteja ocorrendo) com os órgãos policiais. Aqui descreve também as notícias divulgadas baseadas em tais informações.

${ }^{4}$ Foucault (1997), ao falar da polícia, apresenta a secularidade do órgão, que foi pouco alterado no decorrer dos anos, principalmente por ter aliado a função que o sistema jurídico lhe impõe, da procura de culpados e do controle de complôs, com uma função disciplinar de vigilância, agindo de forma intermediária, aonde outras instituições disciplinares (como escolas e quartéis) não chegam.
} 
“criminosos". O que o jornalismo faz, em diversos casos policiais, é apenas reproduzir as informações dadas pelas fontes oficiais. Não somente reproduzindo as notícias, como também o enquadramento dado por tais órgãos. Normalmente, um enquadramento de marginalização do favelado, do fronteiriço e do paraguaio. A vigilância feita pela polícia sobre tais áreas resulta em prisões, já a vigilância jornalística reproduz o poder e a disciplina dos órgãos oficiais, hierarquizando o sistema, desvalorizando e desqualificando o outro - ratificando os conceitos de Foucault, apresentados na sequência.

Entre as já citadas cinco precauções metodológicas de Foucault (2008), uma alerta sobre a importância de estudar o poder no seu ponto mais capilar, onde ele corporifica-se em técnicas materiais. Dessa forma, uma das questões que se destacam no jornal Gazeta do Iguaçu ao estudarmos o uso da linguagem jornalística e do enquadramento dado pelo jornal diz respeito aos brasiguaios ${ }^{5}$.

Para manter a disciplina e as relações de poder instituídas o jornal trata, por exemplo, do problema de saúde local como algo causado pelos brasiguaios. A manchete do dia 22 de junho de 2006 traz esse tratamento: "Brasiguaios sobrecarregam sistema de saúde em Foz". Mais abaixo, no subtítulo, lê-se: "Dos 600 mil atendimentos anuais na cidade, mais de 180 mil são a brasiguaios e a Paraguaios". No fim da matéria lê-se: "A exigência da documentação como o cartão SUS, do comprovante de residência e documento pessoal passa a ser exigida a partir desta quinta-feira (22). Pacientes não residentes em Foz, exceto turistas, não serão atendidos." Mais uma vez a disciplina efetua "uma suspensão, nunca total, mas também nunca anulada, do direito" (FOUCAULT, 1997), pois:

Enquanto os sistemas jurídicos qualificam os sujeitos de direito, segundo normas universais, as disciplinas caracterizam, classificam, especializam; distribuem ao longo de uma escala, repartem em torno de uma norma, hierarquizam os indivíduos em relação uns aos outros, e, levando ao limite, desqualificam e invalidam. (FOUCAULT, 1997: 183)

Este caso apresentado exemplifica as palavras de Foucault ao hierarquizar, classificar, caracterizar ao colocar em patamares diferentes turistas, população local e brasiguaios/paraguaios: "O objetivo da exigência do comprovante de residência é proporcionar à população local um melhor atendimento", arremata o jornal.

\footnotetext{
${ }^{5}$ Junção de brasileiro e paraguaio. Termo usual na fronteira que define os brasileiros e seus descendentes que moram no Paraguai, principalmente nas províncias fronteiriças do Alto Paraná e Canindeyú. São, em sua maioria, agricultores de origem italiana, alemã e eslava. Estima-se que compreendam 300 mil pessoas.
} 
Ainda em notícias que fazem referência à saúde pública e aos brasiguaios, outra matéria exemplifica uma das precauções metodológicas foucaultianas: analisar a maneira como os fenômenos, as técnicas e os procedimentos de poder atuam nos níveis mais baixos e como se deslocam, se expandem e se modificam para um contexto mais global, de forma ascendente (FOUCAULT, 2008). A notícia é do dia 08 de julho: “Fui bem atendida', diz brasiguaia que deu à luz em posto" ${ }^{6}$. Na matéria a réplica da prefeitura e dos órgãos públicos tem maior destaque que a perda da criança, mas outro aspecto chama a atenção. Depois de a brasiguaia assumir que foi bem atendida, o jornal relembra os:

vultosos investimentos que o sistema de saúde de Foz vem recebendo. É o setor que recebeu mais atenção, justamente por se tratar de uma prioridade para o governo Paulo Mac Donald e apresentar um dos maiores déficits no serviço público quando o prefeito assumiu o cargo, em janeiro de 2005. Toda melhoria implementada [...] promoveu um salto na qualidade do serviço. A capacidade de atendimento, porém, não conseguiu atender à demanda reprimida por tantos anos de descaso e má vontade política. (Ed. 5395, 08 de Julho de 2006)

Evidencia-se um viés opinativo do texto que, pelo menos em teoria, seria basicamente informativo, noticioso. Num relato empírico, sem o uso de dados estruturais que comprovem a "má vontade política", o jornal dá a ideia de avanços capitais no sistema de saúde, com vultosos investimentos feitos pela administração pública. Levando em conta a precaução metodológica de Foucault, citada no parágrafo anterior, o procedimento fica mais visível: dentro de uma notícia que trata de problemas de saúde o jornal ameniza a culpa dos órgãos públicos, isenta-os. Além disso, aproveita-se desse espaço para agir a favor desse poder, relembrando os avanços conduzidos por tal. Nesse caso o jornal torna-se instrumento para se exercer o poder.

\section{“Inuasões" Semióticas}

Analisando os dados do ano de 2006 e, mais especificamente, o corpus de análise, algo que chama atenção é o uso do termo "invasão" no jornal. Aqui, cabe o conceito semiótico de Bakhtin para signo ideológico:

Os signos também são objetos naturais, específicos, e, como vimos, todo produto natural, tecnológico ou de consumo pode tornar-se signo e adquirir, assim, um sentido que ultrapasse suas próprias particularidades. Um signo não existe apenas como parte de uma realidade; ele

\footnotetext{
${ }^{6}$ Dias antes no mesmo jornal a mãe reclamava de negligência por parte dos profissionais do posto de saúde onde dera a luz dentro do banheiro
} 
também reflete e refrata uma outra. Ele pode distorcer essa realidade, ser-lhe fiel, ou apreendêla de um ponto de vista específico, etc. Todo signo está sujeito aos critérios de avaliação ideológica (isto é: se é verdadeiro, falso, correto, justificado, bom, etc.). [...] Cada signo ideológico é não apenas um reflexo, uma sombra da realidade, mas também um fragmento material dessa realidade. Todo fenômeno que funciona como signo ideológico tem uma encarnação material, seja como som, como massa física, como cor, como movimento do corpo ou como outra coisa qualquer. (BAKHTIN, 1981: 32)

Assim, para Bakhtin um signo pode adquirir sentidos diferentes dependendo da realidade onde se insere e de como reflete e refrata outra realidade. Desse modo, duas notícias chamam atenção: “Ambulantes paraguaios 'invadem' ruas de Foz”, do dia 07 de janeiro; e "Policiais 'invadem' residência errada", de 15 de agosto. As duas usam o mesmo "signo ideológico", o termo invasão entre aspas. Mas as duas se referem a realidades muito distintas de invasão. A primeira delas faz grande alarde no título, que ao usar o termo "invasão" chama mais atenção. Nesse caso a palavra dá força para um fato miúdo, ambulantes paraguaios atravessando a fronteira em decorrência do baixo movimento em Ciudad del Este.

Já na matéria de agosto de 2006, "invasão" é empregado em outro contexto, o que muda não só o sentido do termo como o uso das aspas. Escrita pelo mesmo repórter, a matéria usa um conceito mais parecido com aquele encontrado nos dicionários para invasão ${ }^{7}$. O uso das aspas, nesse caso, diminui a gravidade do fato - uma invasão policial ocorrida às 6:30 da manhã. No subtítulo reforça-se a casualidade do acontecimento, descrevendo os policias como "servidores" e o fato como "equívoco": "Depois de causar pânico à família, que teve a casa invadida às 6h30, servidores perceberam o equívoco". Outro indício de casualidade é a editoria onde a notícia foi veiculada, Cidade, e não na editoria específica para casos policiais, Polícia.

\section{Considerações Finais}

A recorrência dos termos "Paraguai" de forma pejorativa e os diversos casos de adulação e/ou amortecimento dos órgãos policias tendem a definir o jornal como instrumento de poder e disciplina, principalmente quanto à constante vigilância imposta à nação vizinha. Não raro o Paraguai e os paraguaios são vistos como desordeiros e criminosos, no plural. Há, visivelmente, uma generalização imposta, que hierarquiza a

\footnotetext{
${ }^{7}$ Segundo o dicionário Houaiss: ato de penetrar (em local, espaço etc.), ocupando-o pela força; migração acompanhada de violência e devastações; ato de alastrar-se e difundir-se maciça e rapidamente. Fonte: Dicionário Houaiss online: http://houaiss.uol.com.br/busca.jhtm?verbete $=$ invas\%E3o\&x=10\&y=4\&stype=k, acessado em 10/07/2010.
} 
sociedade, diminui paraguaios em relação aos brasileiros (aqui considerando os brasiguaios como brasileiros); diminui brasiguaios em relação aos brasileiros; moradores da periferia em relação à classe média ${ }^{8}$.

Além disso, o jornal muitas vezes apresenta matérias em que ficam evidenciados as ações do poder, como os casos apresentados neste artigo que envolviam o poder público municipal e a polícia, de regra elogiadas em seus trabalhos. Isso retira do jornal, como órgão de imprensa, a função de vigilância do poder público para informar a população. $\mathrm{O}$ jornal torna-se meio de propaganda do poder instituído e torna a vigiar outras áreas já extremamente vigiadas, como as favelas, periferias e as cidades da fronteira agindo de forma disciplinadora. Algo que, infelizmente, pode ser observado em diversos outros periódicos de referência nacional.

\section{Referências Bibliográficas}

BAKHTIN, M. Marxismo e Filosofia da Linguagem: Problemas fundamentais do Método Sociológico na Ciência da Linguagem. 2. Ed. São Paulo: Ed. HUCITEC, 1981.

FOUCAULT, M. Microfísica do Poder. 26. Ed. Rio de Janeiro: Edições Graal, 2008.

Vigiar e Punir: Nascimento da Prisão. 16. Ed. Petrópolis: Ed. Vozes, 1997.

${ }^{8}$ Segundo dados do jornal Gazeta do Iguaçu a maior parte do público é masculina (55\%), tem grau de escolaridade primária (41\%), faixa etária entre 25 - 45 anos (36\%) e das classes A (41\%) e B (36\%). Disponível no endereço eletrônico: http://gazeta.inf.br/perfil.php (acessado em 10/07/2010). 